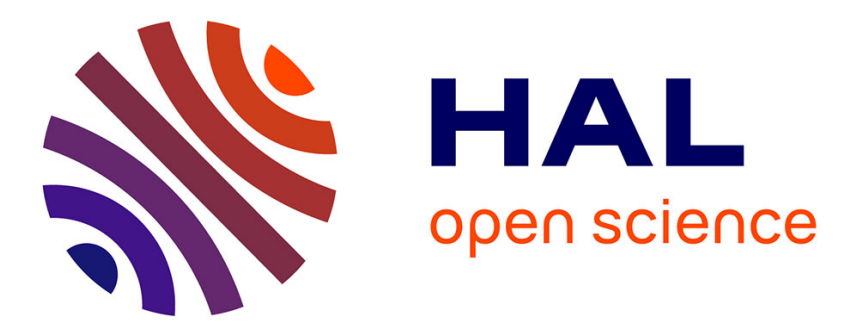

\title{
Implicit and explicit stereotype content associated with people with physical disability: Does sport change anything?
}

Corentin Clément-Guillotin, Odile Rohmer, Cyril Forestier, Philippe

Guillotin, Maxime Deshayes, Fabienne d'Arripe-Longueville

\section{To cite this version:}

Corentin Clément-Guillotin, Odile Rohmer, Cyril Forestier, Philippe Guillotin, Maxime Deshayes, et al.. Implicit and explicit stereotype content associated with people with physical disability: Does sport change anything?. Psychology of Sport and Exercise, 2018, 38, pp.192-201. 10.1016/j.psychsport.2018.06.014 . hal-02079290

\section{HAL Id: hal-02079290 \\ https://hal.science/hal-02079290}

Submitted on 25 Mar 2019

HAL is a multi-disciplinary open access archive for the deposit and dissemination of scientific research documents, whether they are published or not. The documents may come from teaching and research institutions in France or abroad, or from public or private research centers.
L'archive ouverte pluridisciplinaire HAL, est destinée au dépôt et à la diffusion de documents scientifiques de niveau recherche, publiés ou non, émanant des établissements d'enseignement et de recherche français ou étrangers, des laboratoires publics ou privés. 


\section{European Journal of Social Psychology}

Implicit and explicit stereotypes content associated to persons with disability: Does sport can change anything?

\begin{tabular}{|r|l|}
\hline Journal: & European Journal of Social Psychology \\
\hline Manuscript ID & Draft \\
\hline Wiley - Manuscript type: & Research Article \\
\hline \multicolumn{2}{r}{} \\
\hline
\end{tabular}

SCHOLARONE ${ }^{m}$

Manuscripts 
Title: Implicit and explicit stereotypes content associated to persons with disability: Does sport can change anything?

Corentin Clément-Guillotin ${ }^{1}$, Odile Rohmer ${ }^{2}$, Cyril Forestier ${ }^{3}$, Philippe Guillotin ${ }^{4}$, Maxime Deshayes $^{1}$, Fabienne d'Arripe-Longueville ${ }^{1}$

${ }^{1}$ Université Côte d'Azur, LAMHESS, France

${ }^{2}$ Université de Strasbourg, Laboratoire de Psychologie des Cognitions, France

${ }^{3}$ Université Grenoble Alpes, SENS, Saint Martin d'Hères, France

${ }^{4}$ Agence d’Urbanisme de la Région Nantaise, AURAN, France

Running head: Sport and disability stereotypes

Address correspondence to : Corentin Clément-Guillotin, Université Côte d'Azur, Faculté des Sciences du Sport - Laboratoire Motricité, Humaine, Expertise, Sport, Santé (EA 6312), 261, boulevard du Mercantour - BP 3259 - 06205 Nice cedex 3, France. E-mail:

corentin.clementguillotin@yahoo.fr 


\begin{abstract}
This article examines whether practicing sport may influence the stereotype content associated to persons with disability. In three studies, both implicit and explicit stereotypes were assessed for targets with disability compared with targets without disability, targets with disability practicing sport compared with targets without disability, and targets with disability practicing sport compared with targets with disability. This research highlighted negative implicit stereotypes on both warmth and competence, without any change by the sport information, while at the explicit level sports persons with disability were perceived as warmer and more competent than persons with disability. The influence of practicing sport on the stereotype content associated to persons with disability is thus not as consistent as supposed in the literature so far. The results suggest to further examine the implicit stereotype content towards people with disability and what kind of information can really decrease the link between disability and negativity.
\end{abstract}

Keywords: disability, sport, Implicit Association Test, stereotype content model 
Title: Implicit and explicit stereotypes content associated to persons with disability: Does sport can change anything?

Since the late $20^{\text {th }}$ century, multiple mechanisms have been employed to improve social inclusion of persons with disability. One of the major mechanisms was the Convention on the rights of persons with disabilities, adopted by the United Nations General Assembly in 2007, which condemns discrimination against persons with disability in education, employment, or social life for example. Unfortunately, despite positive legislations to ensure equal opportunity for all in our society, persons with disability are still subjected to considerable discrimination and social inequities (Dovidio, Pagotto, \& Hebl, 2011; Rohmer \& Louvet, in press). Such discrimination has been reported especially in the workplace (e.g., Colella \& Varma, 1999; Louvet, 2007). Previous research on social perception has explained this by the fact that persons with disability are generally stereotyped as warm but incompetent (e.g., Fiske, Cuddy, Glick, \& Xu, 2002; Louvet, Rohmer, \& Dubois, 2009; Rohmer \& Louvet 2012, in press). This pattern seems even internalized in persons with disability's mind (Louvet et al., 2009). Furthermore, this line of research showed a negative stereotype on all characteristics, outside of individuals' intentional control and awareness (Rohmer \& Louvet, 2012, in press). The major question is how change these negative representations associated with disability? Recently, a set of studies started working on this important question and demonstrated that that being physically active may have positive effects at an explicit level on perceivers' impressions of persons with disability (Arbour, Latimer, Martin Ginis, \& Jung, 2007; Barg, Armstrong, Hetz, \& Latimer, 2010; Gainforth, O’Malley, Mountenay, \& LatimerCheung, 2013; Kittson, Gainforth, Edwards, Bolkowy, \& Latimer-Cheung, 2013; Tyrrell, Hetz, Barg, \& Latimer, 2010). The present research aimed to further explore how sport practice can increase positive perception toward people with disability. We specifically assessed whether this effect may appear at an implicit level. Because implicit evaluations 
operate outside of awareness and intentional control, they limit socially desirable responding, and promise to better measure the respondents' "true" attitudes and beliefs towards persons with disability, a strongly normatively protected group.

According to the stereotype content model (SCM; Fiske et al., 2002), stereotypes are captured by two universal dimensions: warmth and competence. Warmth refers to social qualities (e.g. warm, friendly) important to anticipate intents of others during social interactions. Competence refers to intellectual qualities (e.g. intelligent, capable) designating how people are able to effectively enact their motives. Fiske et al. (2002) showed that these dimensions derive from competition and status relations between groups, such that noncompetitive groups are perceived as warmer than competitive ones, and high-status groups as more competent than low-status ones. Most of social groups have been portrayed by ambivalent perceptions. Specifically, people with disability have been consistently stereotyped as warm but not competent (Fiske et al., 2002; Kittson et al., 2013; Louvet et al., 2009, Study 1; Rohmer \& Louvet, 2012). For instance, Kittson et al. (2013) showed that a paraplegic target at the first impression was rated with a high warmth and low competence stereotype mix. Negative evaluations toward persons with disability on competence may explain, justify and maintain social inequalities insofar as incompetence is perceived as a valid basis for discrimination (Oldmeadow \& Fiske, 2010). It is therefore essential to improve perception of competence associated to disability, in order to decrease discriminatory behaviors.

In this perspective, recent research suggested that linking disability and physical activity can improve social judgments toward people with disability: previous studies on the exercise stereotype phenomenon showed that, regardless of the exercise status of the perceiver and the sex of the target, targets described as exercising are evaluated more favourably compared with non-exercising targets and control targets with no exercise information 
provided (e.g., Martin, Sinden, \& Fleming, 2000; Martin Ginis, Latimer, \& Jung, 2003; Martin Ginis \& Leary, 2006). More important, a series of studies demonstrated that this exerciser stereotype could be applied to people with disability: physically active people with disability eliciting more positive social perceptions than their non-physically active counterparts (Arbour et al., 2007; Barg et al., 2010; Gainforth et al., 2013; Kittson et al., 2013; Tyrrell et al., 2010). While perceived incompetence attributed to members of discriminated groups has been shown to be particularly resistant to change (Cuddy, Fiske, \& Glick, 2008; Cuddy, Norton, \& Fiske, 2005), Kittson et al. (2013) found that viewing a video of an individual with disability engaging in a physical activity, either sport, exercise, or an activity of daily living, was a means of eliciting high competence and warmth ratings among persons without disability. The low competence pattern generally observed in evaluations towards people with disability was challenged especially when disability was related to sport practice, eliciting in particular the greatest increases in competence attributed to the target. Gainforth et al. (2013) also showed that an exercising target with disability could be judged as competent as the other target described without any disability information. Thus, the physical activity information seems a good strategy to close the gap between evaluations of targets with or without disability. However, the competence-enhancing observed in the physically active targets with disability could be less reliable than expected so far in the literature.

First, previous results were obtained by using Likert-type scales. As Biernat (2003) pointed out in the shifting standards model, when such subjective response scales are used, they may mask the operation of stereotypes because intra-group comparisons are encouraged. So, as shown by Gainforth et al. (2013), a similar level of competence attributed to a physically active target with disability and a target without disability may simply reveal the use of Likert-type scales allowing intra-group comparisons (i.e., the physically active target with disability being perceived as really competent as compared to people with disability, 
while the target without disability being compared to people without disability). Similarly, because of this intra-group comparison phenomenon, the high level of warmth attributed to people with disability may be more pronounced when using Likert-type scales.

Conversely, objective or common rule response scales (e.g., estimated standardized test score, rank orderings) can better maintain a constant meaning across type of targets and contexts. Objective scales fostering comparisons between groups allow to highlight stereotypical process. Thus, they may reduce warmth and competence attributions to people with disability. Indeed, in this case, people with disability and people without disability are directly compared. To our knowledge, studies so far have only used subjective response scales when testing the exercise stereotype phenomenon with the warmth and competence stereotypes associated to individuals with disability. So, in the present research we used objective response scales to find out how strong the warmth dimension associated to people with disability is and how strong the competence-enhancing perceived in physically active individuals with disability is, notably as compared to individuals without disability.

Second, recent studies analyzing the stereotype content of persons with disability showed discrepancies between implicit and explicit measures (Rohmer \& Louvet, 2012, in press). Explicit evaluations were assessed by self-report questionnaires and one fundamental problem with such measures is that they are transparent to the respondent, and therefore sensitive to social desirability concerns. In order to present themselves in a favorable way, many people may not reveal their counter-normative attitudes when asked about socially sensitive issues. In other words, positive evaluations towards persons with disability could lie in the normative pressures pertaining to the expression of non-discrimination. Cambon, Yzerbyt, and Yakimova (2015) showed that members of a high status group rely on compensation in their judgments when groups are in asymmetrical and non-conflicting relation. Compensation was demonstrated in this case as a means to appear non- 
discriminatory for high-status group members. Thus, people without disability, being considered as a legitimate high status group (Dovidio et al., 2011; Rohmer \& Louvet, 2009, 2011), may valorize people with disability on the warmth dimension in a form of magnanimity (see also Cambon \& Yzerbyt, in press).

At the implicit level, people have less opportunity to control their responses and to express positive qualities towards persons with disability to make a good impression of themselves. Indeed, normative pressures to appear non-discriminatory seem less likely to apply (Dovidio et al., 2011; Nosek, 2005). In line with this reasoning, Rohmer and Louvet (2012, in press) found that the mixed stereotype content of people with disability observed at an explicit level was not found when implicit measures were used. Using subliminal primes and a Lexical Decision Task, these authors showed important discrepancies between implicit and explicit measures. Whereas a mixed stereotype appeared on the explicit level (persons with disability were seen as warmer but less competent than persons without disability), they did not found this compensatory pattern on the implicit level (persons with disability were associated with more negativity on both dimensions) (see also Pruett \& Chan, 2006). Such discrepancies between implicit and explicit measures could be also found with physically active targets with disability. Then, the high competence-enhancing associated with the physically active targets with disability at the explicit level might be less pronounced at the implicit level. Thus, it appear fundamental to further explore how disability information may be consistent with other information in mind. More precisely, are we able to relate disability and athletic capacities, while at the same time, the stereotype of persons with disability includes poor capacities, and especially poor physical performance (Ginsberg, Rohmer, \& Louvet, 2012)? This question is important to better understand the gap between good intentions towards disability and persistent discriminatory behaviors.

Present research 
In the present research, we aimed to examine whether the physical activity information has a large impact on the stereotype content associated to people with disability. To this end, the explicit stereotype content as well as the implicit stereotype content were assessed. The implicit stereotype content was assessed using Implicit Associations Tests (IATs) capturing the warmth dimension and the competence dimension. Objective response scales were also used to assess the explicit stereotype content. In particular, we conducted three separate studies comparing the explicit stereotype content and the implicit stereotype content associated to people with disability. We report how we determined our sample size, all data exclusions (if any), all manipulations, and all measures in the study (Simmons, Nelson, \& Simonsohn, 2012).

In Study 1, we aimed to replicate Rohmer and Louvet's (2012) results. While they found that people with disability were associated with less competence and warmth as compared to people without disability at implicit level, one could think that these results were due to the methodology chosen. In their studies, a lexical decision task was used. Conversely, Carlsson and Björklund (2010) conducted IATs comparing warmth and competence related to pre-school teachers and lawyers and found mixed implicit stereotypes for these two groups. One may suppose that univalent implicit stereotype is more likely to appear when using a lexical decision task, while ambivalent implicit stereotype is more likely to appear when using IATs. So, the replication of Rohmer and Louvet's (2012) results with IATs comparing people with disability and people without disability constitutes an important step to better analyze stereotype content of persons with disability.

Then, in Study 2, at both explicit and implicit level, we compared the stereotype content associated to people with disability engaged in a sport activity and people without disability. Based on Rohmer and Louvet's (2012) results, we expected, at the implicit level, that the sport information could not help people with disability to fill the gap on the 
competence dimension with people without disability. Nevertheless, as suggested by previous work (Gainforth et al., 2013; Kittson et al., 2013; Louvet \& Rohmer, 2010), athletes with disability could be perceived as particularly courageous, motivated and effortful in order to push themselves beyond their mental and physical limits and this perception could help them to fill the gap on the competence dimension with people without disability at the explicit level.

Finally, in Study 3, the stereotype content towards people with disability engaging in sport was compared to the stereotype content towards people with disability. Again, we compared results issued from both explicit and implicit paradigms. In line with Kittson et al. (2013), we predicted that sports people with disability would be perceived as more competent and warmer than people with disability at the explicit level and examined whether such pattern could also appear at the implicit level.

\section{Pilot Study}

We conducted a pilot study to determine the most relevant images for each category (i.e., persons with disability, without disability persons, sports persons with disability) used in the following IATs (Greenwald, McGhee, \& Schwartz, 1998). Thirty-three French undergraduate students without disability (18 females and 15 males; $M_{\text {age }}=19.85$ years, $S D=$ 1.03 ) at the University of Nice Sophia Antipolis who did not participate in the main experiments were asked to indicate how they perceived a series of pictures in a questionnaire. This questionnaire was composed of an original pool of pictures, including pictograms, avatars and photos of an individual with disability, a sports person with disability, and an individual without disability. Avatars were created with the website http://www.bitstripsforschools.com/ and photos were taken in the gymnasium and hall way of the faculty with a camera Lumix DMC-SZ10 20 Mpixels. Pictograms were created with the software « Photofiltre ». It was also used to modify the photos and avatars 
(face bluring at -7 and resizing to $760 \times 790$ ). In these photos, avatars and pictograms, the same person with the same background was presented in the three categories (i.e., persons with disability, without disability persons, sports persons with disability).

First, participants were presented the pool of pictures and were asked to indicate the extent to which they associated each picture to Disability on a 7 -point scale $(1=$ not at all disability-linked, 4 = moderately linked to disability, $7=$ absolutely disability-linked). Then, the same pool of pictures was presented and participants were asked to indicate the extent to which they associated each picture to Sport on a 7-point scale $(1=$ not at all sport-linked, $4=$ moderately sport-linked, $7=$ absolutely sport-linked). The five pictures in each category with the most extreme evaluation were kept and pictures' nature was controlled (see Appendix for all stimuli pictures). Specifically, for the « without disabililty persons » category, the five pictures with the lowest disability-linked scores $(M=1.66, S D=0.87)$ and the lowest sportlinked scores $(M=2.02, S D=1.01)$ were kept. For the « sports persons with disability» category, the five pictures with the highest disability-linked scores $(M=5.92, S D=0.87)$ and sport-linked scores $(M=6.56, S D=0.54)$ were kept. For the «persons with disability» category, the five pictures with the highest disability-linked scores $(M=6.50, S D=0.71)$ and the lowest sport-linked scores $(M=2.30, S D=1.28)$ were kept.

Finally, the disability-linked and sport-linked scores of the fifteen pictures kept (see the Appendix) were separately entered into a Picture Category (persons with disability, without disability persons, sports persons with disability) repeated measures analysis of variance (ANOVA), the factor being within subjects. Concerning the disability-linked scores, results showed a main effect of Picture Category, $F(2,64)=339.38, p<.0001, \eta^{2}=.91$. Post hoc Scheffé tests revealed that the "persons with disability" pictures $(M=6.50, S D=0.71)$ and the "sports persons with disability" pictures $(M=5.92, S D=0.87)$ were perceived as more disability-linked than "without disability persons" pictures $(M=1.66, S D=0.87)$. 
The "persons with disability" pictures were more linked to disability than the "sports persons with disability" pictures, $p<.05$.

Concerning the sport-linked scores, the main effect of Picture Category was also significant, $F(2,64)=253.48, p<.0001, \eta^{2}=.89$. Post hoc Scheffé tests showed that the “sports persons with disability" pictures $(M=6.56, S D=0.54)$ were perceived as more sportlinked than the "persons with disability" pictures $(M=2.30, S D=1.28)$ and "without disability persons" pictures $(M=2.02, S D=1.01)$. No difference emerged between the last two types of pictures.

In sum, the pictures of "persons with disability" and "sports persons with disability" kept were more associated to Disability than the pictures of "without disability persons", and the pictures of "sports persons with disability" were more associated to Sport than the pictures of "without disability persons" and "persons with disability", ensuring that this selection of pictures was relevant for our further studies.

\section{Study 1}

Based on Rohmer and Louvet's (2012, in press) studies, we predicted that, compared to persons without disability, persons with disability would be associated with less warmth and with less competence at an implicit level, whereas they would be judged less competent but warmer at an explicit level.

\section{Method}

Participants. On the basis of the effects found in past studies on implicit stereotypes associated to persons with disability (Rohmer \& Louvet, 2012), a medium effect size was expected $(d=0.5)$. With a fixed $\alpha$-level $(.05)$ and a high statistic power of .90 , the required sample size was at least 36 participants. Fifty-seven students without disability (30 women, 27 men, $M$ age $=20.95$ years, $S D=2.36$ years) were recruited on campus and volunteered to 
participate in the study. They completed individually all dependent measures. Informed consent and institutional approval of the protocol were obtained.

\section{Materials}

The Implicit Association Tests. The present implicit measures consisted of two stereotype IATs. Items relative to the categories were based on Fiske et al. (2002) and Carlsson and Björklund (2010). Specifically, the warmth-IAT had the attribute labels Warm and Cold, where the five stimulus words belonging to the Warm category were warm, well intentioned, nice, friendly, honest, while the five stimulus words belonging to the Cold category were cold, evil minded, nasty, unfriendly, dishonest. Similarly, the competence-IAT included the attribute labels Competent and Incompetent, with Competent stimuli consisting of the words competent, efficient, intelligent, independent, able, and Incompetent stimuli consisting of the words incompetent, inefficient, unintelligent, dependent, unable. Except for these differences in attribute labels and stimuli, the two IATs were identical in every detail. The target labels consisted of persons with disability and without disability persons. The corresponding stimuli for these categories were respectively five pictures selected in the pilot study. Thus, the IATs designed for the current research measured implicit associations by measuring the speed of association between disability and warmth (versus coldness), and without disability and coldness (versus warmth) on the one hand; the speed of association between disability and competence (versus incompetence), and without disability and competence (versus incompetence) on the other hand. The order in which participants performed the warmth-IAT and the competence-IAT was counterbalanced between participants.

The IATs were administered on a computer. It consisted of seven stages of word/ picture categorization trials, with 20 trials for stages $1,2,3$, and 6 , and 40 trials for stages 4 , 5, and 7. In stage 1, participants classified pictures presented individually on the computer 
screen as belonging to one of two categories, persons with disability or without disability persons. If the picture presented in the middle of the screen belonged to the category shown on the right of the screen (i.e., "without disability persons"), the participant responded by pressing the ' 7 ' key. If the picture flashed in the middle of the screen belonged to the category shown on the left of the screen (i.e., "persons with disability"), then the participant responded by pressing the 'e' key. In stage 2, a second pair of concepts was introduced. The participants categorized words shown in the middle of the screen (e.g., "well intentioned", "unfriendly") according to whether they belonged to the category shown on the right (i.e., "cold") or the left (i.e., "warm"). In stages 3 and 4 (data-collection blocks), the categories from the first two stages were superimposed. The ' 7 ' key was used to respond to pictures/words that referred to "persons with disability" or "warm," while the 'e' key was used for pictures/words that referred to "without disability persons" or "cold". In stage 5, participants categorized pictures from the first stage but used the opposite keys to respond. Finally, in stages 6 and 7 (datacollection blocks), the categories were again superimposed, but the key assignments for one pair were reversed from their position in the third stage. The order of presentation of the blocks was counterbalanced between subjects, with stages 1, 3, and 4 switched with stages 5 , 6, and 7, respectively. Each stimulus item was displayed until its correct response was made. The next stimulus item then followed after a 250 milliseconds intertrial interval. The computer recorded elapsed time between the start of each stimulus item's presentation and occurrence of the correct keyboard response.

Explicit Measures. Based on Carlson and Björklund research (2010), participants were asked to rate how strongly they associated a series of traits with persons with disability or without disability persons on a 7-point scale $(1=$ Much more strongly with persons with disability, 4 = Equally strongly with without disability persons and persons with disability, 7 = Much more strongly with without disability persons). The same five stimulus words as in 
the two stereotype IATs belonging respectively to the Warm category and the Competent category were used. The reliability of both scales was acceptable (Cronbach's alpha $>.69$ for both scales).

\section{Procedure}

Participants were led to an individual room and were informed that the experiment was computer-administered. After providing informed consent, participants performed the two stereotype IATs and were instructed to complete each trial as quickly and as accurately as possible. After completing the two IATs, participants filled out the explicit measures and provided demographic data. They were then debriefed and thanked for their participation.

\section{Results}

According to procedures recommended by Greenwald, Nosek, and Banaji (2003), we deleted trials greater than 10,000 milliseconds. All participants were included in the final sample because none had more than $10 \%$ of trials with latency less than 300 milliseconds. For each stereotype IAT, the new scoring algorithm was used to compute IAT scores (Greenwald et al., 2003), in which the standard deviations within conditions were applied to calculate the $D$ scores. Concerning the warmth-IAT, higher $D$ scores reflect more implicit association by showing greater facilitation when associating persons with disability with warm words and without disability persons with cold words. Concerning the competence-IAT, higher $D$ scores reflect more implicit association by showing greater facilitation when associating persons with disability with incompetent words and without disability persons with competent words. Finally, the mean scores relative to warmth and competence dimensions collected across the explicit measures were calculated for each participant.

Implicit effects. Using independent one-sample $t$-test, the mean $D$ score was contrasted against a value of zero $(0=$ implicit indifference in the association strengths between response blocks) to assess the presence of automatic associations between concepts 
in participants in general. In the warmth-IAT, overall participants implicitly associated without disability persons with warmth and persons with disability with coldness $(M=-0.56$, $S D=0.40), t(56)=-10.68, p<.0001, d=1.40$. In the competence-IAT, again, participants implicitly associated without disability persons with competence and persons with disability with incompetence $(M=0.57, S D=0.39), t(56)=11.25, p<.0001, d=1.46$.

Explicit effects. Using also independent one-sample $t$-test, the mean explicit stereotype score relative to warmth and competence was contrasted against the midpoint of the scale (i.e., 4). On average, participants explicitly linked warmth more with persons with disability than with without disability persons $(M=3.89, S D=0.35), t(56)=-2.25, p<.05, d$ $=0.31$. On the contrary, participants explicitly linked competence more with without disability persons than with persons with disability $(M=4.66, S D=0.47), t(56)=10.44, p<$ $.0001, d=1.40$.

Explicit-Implicit Relationship. The $D$ scores in the warmth-IAT did not correlate with the explicit stereotype scores relative to warmth $(r=-.23, p=.09)$. Also, the $D$ scores in the competence-IAT did not show a significant correlation with the explicit stereotype scores relative to competence $(r=.11, p=.40)$.

\section{Discussion}

The results of the present study were consistent with those of Rohmer and Louvet (2012, in press). Using another methodology, they confirmed that persons with disability were implicitly associated with less positivity than without disability persons on both warmth and competence qualities. Moreover, relative to without disability persons, persons with disability were associated with higher warmth but with lower competence at an explicit level. These results stressed the strength of the fit between warmth and disability at an explicit level. Indeed, an ambivalent judgment with high scores on warmth still appeared towards persons with disability, even when participants were encouraged to make a choice in their traits 
associations between persons with disability and without disability persons. It suggests that the association between warmth and disability is quite robust at the explicit level.

Additionally, results indicated that there were no significant correlations between implicit and explicit scores for both competence and warmth. This finding is consistent with previous results repeatedly emphasizing that relations between explicit and implicit measures tend to be weak (Rohmer \& Louvet, 2012; Nosek, 2005).

To summarize, Study 1 clearly confirmed discrepancies between implicit and explicit stereotypes: the ambivalent stereotype associated with disability at the explicit level (positive and negative) was no more ambivalent at an implicit level but totally negative. Discrepancies between explicit and implicit attitudes can be explained by societal pressure against prejudice and discrimination in our society. Overt negative attitudes toward persons with disability are unacceptable, these persons belonging to a strongly normatively protected group.

Consequently, positive evaluations on personal qualities are deliberately endorsed as an overcompensation strategy based on the motivation to appear 'politically correct' (Dambrun \& Guimond, 2004). By contrast, the implicit level gives people a reduced opportunity to control their answers in a socially desirable way and automatic attitudes towards disability were then unambiguously revealed. This underlines the need to further explore this question in order to highlight how to make real change in the way persons with disability are considered. In this line, recent works on the stereotype content associated to persons with disability suggested that a sport information could elicit a competence-enhancing in the explicit perception of persons with disability, as compared to persons with disability without any sport information (Gainforth et al., 2013; Kittson et al., 2013). In the following study, we examined how strong this competence-enhancing could be by investigating both implicit and explicit evaluations and forcing participants to make relative judgments between sports persons with disability and without disability persons. 


\section{Study 2}

In Study 2, we assessed stereotyped judgment towards sports persons with disability at both implicit and explicit level, as compared to persons without disability. Rohmer and Louvet (in press) showed that disability is particularly associated with a lack of competence when a competence-relevant context is activated (work context in their study). In line with these preliminary results, we expected that the sport context, associated with competitiveness, power, and efficiency as the work context, does not increase positive judgments at the implicit level. Nevertheless, as suggested by previous work (Gainforth et al., 2013; Kittson et al., 2013), athletes with disability could be perceived as particularly courageous, motivated and effortful in order to push themselves beyond their mental and physical limits and this perception could help them to fill the gap on the competence dimension with people without disability at the explicit level.

\section{Method}

Participants. Sixty-one students without disability (37 women, 24 men, $M$ age = 21.46 years, $S D=3.36$ years) were recruited on campus and volunteered to participate in the study. They completed individually all dependent measures. Informed consent and institutional approval of the protocol were obtained.

Materials and procedure. The same tasks with the same procedure as in Study 1 were presented to participants. Only the target labels provided in the two stereotype IATs and the explicit measures were modified. The target labels consisted of sports persons with disability and without disability persons. For the explicit measures, participants were asked to rate how strongly they associated the same series of traits as in Study 1 with sports persons with disability or without disability persons on a 7-point scale $(1=$ Much more strongly with without disability persons, $4=$ Equally strongly with without disability persons and sports persons with disability, $7=$ Much more strongly with sports persons with disability). 


\section{Results}

Like in Study 1, the procedures recommended by Greenwald et al. (2003) were followed. All participants were included in the final sample. Concerning the warmth-IAT, higher $D$ scores reflect more implicit association by showing greater facilitation when associating sports persons with disability with warm words and without disability persons with cold words. Concerning the competence-IAT, higher $D$ scores reflect more implicit association by showing greater facilitation when associating sports persons with disability with competent words and without disability persons with incompetent words. Finally, the mean scores relative to warmth and competence dimensions collected across the explicit measures were calculated for each participant.

Implicit effects. In the warmth-IAT, one-sample $t$-test reliably showed that overall participants implicitly associated without disability persons with warmth and sports persons with disability with coldness $(M=-0.48, S D=0.41), t(60)=-9.08, p<.0001, d=1.17$. In the competence-IAT, one-sample $t$-test again revealed that overall participants implicitly associated without disability persons with competence and sports persons with disability with incompetence $(M=-0.56, S D=0.38), t(60)=-11.58, p<.0001, d=1.47$.

Explicit effects. On average, participants explicitly linked warmth more with sports persons with disability than with without disability persons $(M=4.14, S D=0.49), t(60)=$ $2.21, p<.05, d=0.27$. However, contrary to our expectations, participants explicitly linked competence more with without disability persons than with sports persons with disability $(M$ $=3.48, S D=0.68), t(60)=-5.98, p<.0001, d=0.76$.

\section{Discussion}

Study 2 aimed to test how additional information about targets with disability can change the subsequent judgment towards them. More precisely, we introduced a sport context, recognized as rewarding for persons with disability (Gainforth et al., 2013; Génolini, 2007; 
Kittson et al., 2013) and we tested how this specific context can decrease the gap between both explicit and implicit judgments towards individuals with and without disability. In line with previous work, we expected more positive evaluation on competence, at least at the explicit level. Unfortunately, results showed that, when sports persons with disability and persons without disability were compared at both implicit and explicit level, the sport information had not a significant effect on impression.

On the one hand, sports persons with disability were implicitly associated overall with less positivity than without disability persons on both warmth and competence dimensions. On the other hand, relative to without disability persons, sports persons with disability were associated with higher warmth but with lower competence on the explicit level. The same results were found in Study 1 when persons with disability and without disability persons were compared (see also Rohmer \& Louvet, 2012, in press). So, it seems that the disability category has a stronger impact on relative judgments than the sport information. These findings are consistent with previous research suggesting that stereotypes against persons with disability are resisting to changes, although the situational context can be commonly very positive (Louvet \& Rohmer, 2016). Nevertheless, an alternative hypothesis could potentially explain our results: it can be possible that the information about sport was not properly handled and thus participants only focused their impression on comparisons between targets with and without disability. Study 3 aimed to disentangle these alternative hypotheses: all targets are presented as disabled in order to better test the sport information on subsequent judgments.

\section{Study 3}

This study aimed at comparing the mixed stereotype content generally associated to sports persons with disability relative to persons with disability (without additional information) at both implicit and explicit level. Based on Kittson et al.'s (2013) results, we 
predicted that sport information can enhance positive impression about persons with disability. Consequently, sports persons with disability would be associated to higher competence and higher warmth at the explicit level relative to persons with disability. Additionally, we wanted to make sure that activation of a sport context cannot increase positive association between disability and both warmth and competence at the implicit level.

\section{Method}

Participants. Sixty-three students without disability (29 women, 34 men, $M$ age = 21.33 years, $S D=2.16$ years) at Nice Sophia Antipolis University were recruited on campus and volunteered to participate in the study. They completed individually all dependent measures. Informed consent and institutional approval of the protocol were obtained.

Materials and procedure. The same tasks with the same procedure as in Study 1 and Study 2 were presented to participants. Only the target labels provided in the two stereotype IATs and the explicit measures were modified. The target labels consisted of sports persons with disability and persons with disability. For the explicit measures, participants were asked to rate how strongly they associated the same series of traits as in Study 1 and Study 2 with persons with disability or sports persons with disability on a 7-point scale $(1=$ Much more strongly with persons with disability, $4=$ Equally strongly with persons with disability and sports persons with disability, $7=$ Much more strongly with sports persons with disability).

\section{Results}

The same procedures as in Study 1 and Study 2 were followed. All participants were included in the final sample. Concerning the warmth-IAT, higher $D$ scores reflect more implicit association by showing greater facilitation when associating sports persons with disability with warm words and persons with disability with cold words. Concerning the competence-IAT, higher $D$ scores reflect more implicit association by showing greater facilitation when associating sports persons with disability with competent words and persons 
with disability with incompetent words. Finally, the mean scores relative to warmth and competence dimensions collected across the explicit measures were calculated for each participant.

Implicit effects. In the warmth-IAT, one-sample $t$-test showed that overall participants had no difference in the association strengths $(M=0.01, S D=0.56), t(62)=0.13, p>.05$. In the competence-IAT, results showed also that overall participants had no difference in the association strengths $(M=0.01, S D=0.48), t(62)=0.15, p>.05$.

Explicit effects. On average, participants explicitly linked warmth more with sports persons with disability than with persons with disability $(M=4.11, S D=0.33), t(62)=2.78, p$ $<.01, d=0.33$. Similarly, participants explicitly linked competence more with sports persons with disability than with persons with disability $(M=4.69, S D=0.57), t(62)=9.58, p<$ $.0001, d=1.21$.

\section{Discussion}

The major aim of study 3 was further testing the extent to which linking disability and sport can increase positive impression at both explicit and implicit level. Results confirmed our assumptions suggested by previous work (Kittson et al., 2013): sports persons with disability were associated to higher warmth and, especially, higher competence than persons with disability (without additional information). However, this result appeared only at an explicit level and failed to emerge at an implicit level. Overall, participants did not show difference in the association strengths in the warmth-IAT as well as in the competence-IAT, suggesting that the positive effect of the sport information on the explicit level did not penetrate non-conscious information's treatments. It was as if it is impossible to deal with disability information and sport information simultaneously. Consequently, only information about disability remains a priority to form an implicit impression. Previous studies suggested that the gap between disability and work remains vast (Boman, Kjellberg, Danermark, \& 
Boman, 2015; Lo \& Ville, 2013), our results highlighted a similar gap between disability and sport. We can think that automatic associations between disability and all competitive context is difficult to make.

\section{General Discussion}

The main aim of this set of studies was to investigate how further positive information, in addition to those about disability, can moderate negative stereotypes towards persons with disability. Our ambition was to resolve the gap between disability and perceived

performances. While the sport information has been consistently shown to be a good strategy for people with disability to elicit positive attitudes, expressly on the competence dimension (e.g., Kittson et al., 2013), the contribution of the present research was to determine the extent and effectiveness of this strategy. To investigate this question, we compared explicit attitudes, traditionally used in this area, to implicit attitudes. As a matter of fact, to present themselves in a favorable way, many people may not reveal their counter-normative attitudes when asked about disability. In this case, their positive evaluations would not manifest themselves when examining implicit evaluations, operating in an automatic way. Based on previous results and empirical paradigms (Rohmer and Louvet, 2012, in press), we predicted that the competenceenhancing generally observed in the sports targets with disability could be more likely to appear at the explicit level than at the implicit level, that may explain persistent difficulties faced by people with disability to valorize their competence. Overall, our findings support these predictions. A complementary aim of this research was to investigate explicit and implicit stereotypes towards disability with other methodologies than that used by Rohmer and Louvet (2012). Thus, Implicit Associations Tests were selected at the implicit level (Wittenbrink \& Schwarz, 2007) and objective scales at the explicit level (Biernat, 2003).

On the one hand, Study 1 demonstrated that persons with disability were implicitly associated with less positivity than without disability persons on both warmth and competence 
dimensions. These results are consistent with Rohmer and Louvet (2012, in press) who showed, using a sequential paradigm, that persons with disability were associated with less competence and less warmth than persons without disability. It was fundamental to confirm Rohmer and Louvet results because Carlsson and Björklund (2010) found mixed implicit stereotypes using IATs comparing pre-school teachers with lawyers. We could have expected that Rohmer and Louvet's (2012) results were dependent on the specific paradigm used. So the replication of their previous results with IATs was important. All in all, these results showed that IAT seems a good and group-sensitive methodology to investigate the implicit stereotype content of social groups.

On the other hand, at the explicit level, previous research on social perception consistently showed that persons with disability are generally stereotyped as warm but incompetent (e.g., Fiske et al., 2002; Louvet et al., 2009; Rohmer \& Louvet, 2012). These studies used Likert-type scales. As Biernat (2003) pointed out, when such subjective response scales are used, they may mask stereotyping' process because intra-group comparisons are encouraged. Conversely, objective scales which are "common rule" in nature maintain a constant meaning across type of targets and contexts. Objective scales, like associating traits between two groups, allow comparisons between groups and, thus, are more likely to highlight stereotypes. In contrast with previous research, objective response scales were used in the present studies to allow inter-group comparisons. Study 1 showed that, relative to without disability persons, persons with disability were associated with higher warmth but with lower competence on the explicit level. Consequently, the fact that a mixed stereotype content still portrayed persons with disability, even when participants were encouraged to make a choice in their traits associations between persons with disability and without disability persons, suggests that the association between warmth and disability is quite robust at the explicit level. 
In Study 1, this overall discrepancy between responses obtained using implicit and explicit measures was also revealed by the fact that $D$ scores did not correlate with the explicit stereotype scores. This suggests that the implicit level and the explicit level are two distinct levels. As mentioned earlier, self-reported stereotypes associated to persons with disability can be distorted by social pressures, whereas implicit measures offer less opportunity to deliberately control responses. To corroborate our results, we could mention Wilson and Scior' work (2015) showing that implicit attitudes towards individuals with intellectual disabilities were somewhat negative and not significantly associated with positive explicit attitudes reported. This suggests that the discrepancy between implicit and explicit level could be quite robust regarding people with disabilities, and not specific to a specific impairment.

However, these discrepant results obtained between the explicit level and the implicit level are not consistent with Carlsson and Björklund (2010). They found that the stereotype content of lawyers and preschool teachers were mixed in the same direction at the explicit level as well as at the implicit level. This inconsistency between these previous results and those obtained in the present research can be explained by specificities of groups retained in each work (Nosek, 2005). While stating negative views about persons with disability seems socially sensitive, this may be less the case of lawyers or preschool teachers. To this matter, Carlsson and Björklund (2010) took care in a pilot study to identify two groups that people do not consider socially sensitive to express negative views about and found that lawyers and preschool teachers met well these criteria. Conversely, the mixed explicit stereotype about persons with disability may more connect to social desirability and fit with normative pressures against prejudice and discrimination (Crandall, Eshleman, \& O’Brien, 2002). As shown on the implicit level evicting socially desirable responses, this could be interesting in future research to manipulate this social desirability at the explicit level and examine whether 
this mixed explicit stereotype about persons with disability would change when people are encouraged to distance from normative pressures to be non-discriminatory.

Moreover, recent works on stereotypes towards persons with disability suggested that sport information elicit notably a competence-enhancing in the explicit perception of persons with disability (e.g., Gainforth et al., 2013; Kittson et al., 2013). Study 3 confirmed these previous results at the explicit level, showing that sports persons with disability were associated to higher warmth and, especially, higher competence than persons with disability with no additional information. However, relative to persons without disability, sports persons with disability were associated with higher warmth but still with lower competence (Study 2). This suggests that the sport information has an influence on the explicit social evaluation of persons with disability, but only when they are compared to persons with disability generally. In this case, the sport information seems to help persons with disability to distance from negative representations of disability. In line with this reasoning, the pilot study showed that the "sports persons with disability" pictures used were less linked to disability than the "persons with disability" pictures.

However, when persons with disability were compared to without disability persons with objective response scales, the sport information was less powerful. As shown by Gainforth et al. (2013), the sport information may seem to help to close the gap in impression formation between targets with disability and those without disability when using Likert-type scales. But in more restraining conditions with objective response scales used in our work, then the sport information seems much less strong. Overall, the same pattern was found for persons with disability and sports persons with disability in Studies 1 and 2 (i.e., higher warmth and lower competence), suggesting that sports persons with disability are more linked in mind to the disability category than to the sport category. 
Unfortunately, at the implicit level, results were even less optimistic. Studies 1 and 2 showed that persons with disability were associated with less positivity than without disability persons on both warmth and competence. In other words, inputting information concerning a sport activity did not help to increase positive attitudes at the implicit level. Similar to explicit judgments, the same implicit negative pattern was found, whether or not practicing sport was added, suggesting again that sports persons with disability are more associated with impairments than with physical capacities. To this respect, White, Jackson, and Gordon (2006) also showed that implicit evaluations towards athletes with disability were consistently negative when compared to without disability athletes.

Persistent difficulties to associate disability and performance were further highlighted in Study 3, showing that the sport information had no effect on the implicit level, when sports persons with disability were compared to generally persons with disability. While the sport information was associated with an increase of warmth and competence at the explicit level, no valorization emerged at the implicit level. This suggests that the positive explicit effect of the sport information is rather artificial, doubtless due to social pressures to consider it is admirable to practice sport notwithstanding disability, but this specific valorization did not change the automatic association in mind between disability and incapacities. It seems that, at the implicit level, persons with disability are summed up to impairments and the sport information cannot help these persons to gain positivity.

However, Dionne, Gainforth, O’Malley, and Latimer-Cheung (2013) found more encouraging results, suggesting that the exerciser stereotype exists implicitly and may undermine negative attitudes towards people with disability. They showed that without disability participants held more positive attitudes towards active versus inactive people with disability. Nevertheless, Dionne et al.'s (2013) study differs from our Study 3. These authors compared active versus inactive people with disability, whereas we compared active people 
with disability versus people with disability with no additional information. Consequently, Dionne et al.'s (2013) results may be explained by even more negative attitudes towards inactive people with disability rather than by more positive impressions towards active people with disability. If this is the case, additional negative information concerning targets with disability should have a greater impact on judgments at the implicit level, than positive information. To this respect, Rohmer and Louvet (in press) showed that a professional context do not increase implicit attitudes towards persons with disability. They explained this result, by the persistent perceived gap between disability and performance.

At this step of the investigation, it would be interesting to examine individual variables that could moderate the implicit patterns. First, we used a sample of without disability students as perceivers. As people tend to have univalent positive stereotypes of their ingroups (Carlsson \& Björklund, 2010; Fiske et al., 2002), one may argue that results showing more warmth and competence towards people without disability as compared to people with disability (with a sport information or not) may reveal pro-ingroup favoritism. Then, it could be interesting to further examine implicit stereotyping of people with disability, in order to test whether pro-ingroup favoritism can be revealed. This question is interesting because previous results showed that participants with disability explicitly devalorized their own group, by describing themselves as less competent than persons without (Louvet et al., 2009). In a complementary way, very little research exists on the link between implicit attitudes and familiarity with disability. Some results again suggested difficulties to relate disability and implicit positive attitudes, regardless participants' contacts with individuals with disabilities (Dionne et al., 2013; Wilson \& Scior, 2015). This intriguing issue merits further investigation. Concerning the power of the sport information combined to disability information in how human brains process these information, results obtained in this work appear quite disappointing. It suggests that sports persons with disability are not a social group well 
elaborated. Despite some improvements, practicing sport by people with disability as well as representing persons with disability practicing sports in the media is rather scarce (Jaarsma, Dijkstra, Geertzen, \& Dekker, 2014; Malone, Barfield, Brasher, \& Ed, 2012; Smith \& Sparkes, 2012). Reinforcing learning of the association between some sport information and people with disability should be an option to increase positive impression in mind. With some time, effort, or intensity of experience, the implicit system may change in an enduring way (Blair, 2002; Devine, Forscher, Austin, \& Cox, 2012; Dovidio et al., 2011). For instance, Devine et al. (2012) showed that a 12-week longitudinal intervention allowed positive changes in implicit race bias. To this respect, future research should investigate whether a strong and long-term exposure to sports people with disability, or other positive situations, would produce enduring change in the implicit stereotype content associated to persons with disability. In a more ecological perspective, using media to show more people with disability engaged in work, in sport or in an artistic activities, can facilitate associations between disability and positive characteristics. To combat discrimination and social exclusion, to promote equal rights for all humans, with and without disability, one can be able to consider that disability is not a stigma or a marker holding by unfortunate people but a relative and flexible characteristic, likely to dissolve in valued context. 
Arbour, K., Latimer, A. M, Ginis, K., \& Jung, M. (2007). Moving beyond the stigma: The impression formation benefits of exercise for individuals with a physical disability. Adapted Physical Activity Quarterly, 24(2), 144-159. doi: 10.1123/apaq.24.2.144

Barg, C., Armstrong, B., Hetz, S., \& Latimer, A. (2010). Physical disability, stigma, and physical activity in children. International Journal of Disability, Development and Education, 57(4), 371-382. doi: 10.1080/1034912X.2010.524417

Biernat, M. (2003). Toward a broader view of social stereotyping. American Psychologist, 58(12), 1019-1027. doi: 10.1037/0003-066X.58.12.1019

Blair, I. (2002). The malleability of automatic stereotypes and prejudice. Personality and Social Psychology Review, 6(3), 242-261. doi: 10.1207/S15327957PSPR0603_8

Bohner, G., \& Dickel, N. (2011). Attitudes and attitude change. Annual Review of Psychology, 62, 391-417. doi: 10.1146/annurev.psych.121208.131609

Boman, T., Kjellberg, A., Danermark, B., \& Boman, E. (2015). Employment opportunities for persons with different types of disability. European Journal of Disability Research, 9, 116129. doi:10.1016/j.alter.2014.11.003

Cambon, L., \& Yzerbyt, V. (in press). Compensation is for real: Evidence from existing groups in the context of actual relations. Group Processes \& Intergroup Relations. doi: $10.1177 / 1368430215625782$

Cambon, L., Yzerbyt, V., \& Yakimova, S. (2015). Compensation in intergroup relations: An investigation of its structural and strategic foundations. British Journal of Social Psychology, 54(1), 140-158. doi: 10.1111/bjso. 12067

Carlsson, R., \& Björklund, F. (2010). Implicit stereotype content: Mixed stereotypes can be measured with the implicit association test. Social Psychology, 41(4), 213-222. doi: $10.1027 / 1864-9335 / \mathrm{a} 000029$ 
Colella, A., \& Varma, A. (1999). Disability-job fit stereotypes and the evaluation of persons with disabilities at work. Journal of Occupational Rehabilitation, 9(2), 79-95. doi: 10.1023/A:1021362019948

Crandall, C.S., Eshleman, A., \& O’Brien, L. (2002). Social norms and the expression and suppression of prejudice: the struggle for internalization. Journal of Personality and Social Psychology, 82, 359-378. doi:10.1037/0022-3514.82.3.359

Cuddy, A. J. C., Fiske, S. T., \& Glick, P. (2008). Warmth and competence as universal dimensions of social perception: The stereotype content model and the BIAS map. In M. P. Zanna (Ed.), Advances in experimental social psychology (Vol. 40, pp. 61-149). New York, NY: Academic Press.

Cuddy, A. J. C., Norton, M. I., \& Fiske, S. T. (2005). This old stereotype: The pervasiveness and persistence of the elderly stereotype. Journal of Social Issues, 61, 267-285. doi: $10.1111 / \mathrm{j} .1540-4560.2005 .00405 . \mathrm{x}$

Devine, P. G., Forscher, P. S., Austin, A. J., \& Cox, W. T. L. (2012). Long-term reduction in implicit race bias: A prejudice habit-breaking intervention. Journal of Experimental Social Psychology, 48(6), 1267-1278. doi: 10.1016\%2Fj.jesp.2012.06.003

Dionne, C. D., Gainforth, H. L., O’Malley, D. A., \& Latimer-Cheung, A. E. (2013). Examining implicit attitudes towards exercisers with a physical disability. The Scientific World Journal. doi: $10.1155 / 2013 / 621596$

Dovidio, J. F., Pagotto, L., \& Hebl, M. R. (2011). Implicit attitudes and discrimination against people with physical disabilities. In R. L. Wiener, S. L. Willborn, R. L. Wiener, S. L. Willborn (Eds.), Disability and aging discrimination: Perspectives in law and psychology (pp. 157-183). New York, NY US: Springer Science + Business Media. doi:10.1007/978-1-44196293-5_9 
Fiske, S., Cuddy, A., Glick, P., \& Xu, J. (2002). A model of (often mixed) stereotype content: Competence and warmth respectively follow from perceived status and competition. Journal of Personality and Social Psychology, 82(6), 878-902. doi: 10.1037//0022-3514.82.6.878

Gainforth, H., O'Malley, D., Mountenay, T., \& Latimer-Cheung, A. (2013). Independence and physical activity status moderate stereotypes toward people with a physical disability. International Journal of Sport and Exercise Psychology, 11(3), 244-257. doi: 10.1080/1612197X.2013.749001

Génolini, J.P. (2007). Handicap mental et personnalité sportive. Cahiers Internationaux de Psychologie Sociale, 75-76, 93-104. doi: 10.3917/cips.075.0093

Ginsberg, F., Rohmer, O., \& Louvet, E. (2012). Disability and elderly stereotype priming influence on motor performance: Similar or specific effects? Perceptual and Motor Skills, 114, 397-406. https://doi.org/10.2466/07.17.PMS.114.2.397-406

Greenwald, A., McGhee, D., \& Schwartz, J. (1998). Measuring individual differences in implicit cognition: The implicit association test. Journal of Personality and Social Psychology, 74(6), 1464-1480. http://dx.doi.org/10.1037/0022-3514.74.6.1464

Greenwald, A., Nosek, B., \& Banaji, M. (2003). Understanding and using the Implicit Association Test: I. An improved scoring algorithm. Journal of Personality and Social Psychology, 85(3), 197-216. doi: 10.1037/0022-3514.85.2.197

Jaarsma, E.A., Dijkstra, P.U., Geertzen, J.H.B., \& Dekker, D. (2014). Barriers to and facilitators of sports participation for people with disabilities: a systematic review. Scandinavian Journal of Medicine \& Science in Sports, 24(6), 871-881. doi: 10.1111/sms.12218

Kittson, K., Gainforth, H., Edwards, J., Bolkowy, R., \& Latimer-Cheung, A. (2013). The effect of video observation on warmth and competence ratings of individuals with disability. Psychology of Sport and Exercise, 14(6), 847-851.

doi:10.1016/j.psychsport.2013.07.003 
Lo, S. H., \& Ville, I. (2013). The “employability” of disabled people in France: A labile and speculative notion to be tested against the empirical data from the 2008 "Handicap-Santé" study. European Journal of Disability Research, 7, 227-306. doi:10.1016/j.alter.2013.09.007

Louvet, E. (2007). Social judgment toward job applicants with disabilities: Perception of personal qualities and competences. Rehabilitation Psychology, 52(3), 297-303. doi: 10.1037/00905550.52 .3 .297

Louvet, E., \& Rohmer, O. (2016). Evaluation des personnes en situation de handicap en milieu éducatif et professionnel : approche expérimentale. Nouvelle Revue de l'Adaptation et de la Scolarisation, 74, 145-159.

Louvet, E., Rohmer, O., \& Dubois, N. (2009). Social judgment of people with disability in the workplace. Swiss Journal of Psychology, 68(3), 153-159. doi: 10.1024/1421-0185.68.3.153

Malone, M. A., Barfield, J. P., Brasher, J. D., \& Ed, M. A. (2012). Perceived benefits and barriers to exercise among persons with physical disabilities or chronic health conditions within action or maintenance stages of exercise. Disability and Health Journal, 5(4), 254-260. doi: 10.1016/j.dhjo.2012.05.004

Martin Ginis, K. A., Latimer, A. E., \& Jung, M. E. (2003). No pain no gain? Examining the generalizability of the exerciser stereotype to moderately active and excessively active targets. Social Behavior and Personality, 31, 283-290. doi: 10.2224/sbp.2003.31.3.283

Martin Ginis, K. A. M., \& Leary, M. R. (2006). Single, physically active, female: The effects of information about exercise participation and body weight on perceptions of young women. Social Behavior and Personality, 34, 979-990. doi: 10.2224/sbp.2006.34.8.979

Martin, K. A., Sinden, A. R., \& Fleming, J. C. (2000). Inactivity may be hazardous to your image: The effects of exercise participation on impression formation. Journal of Sport \& Exercise Psychology, 22, 283-291. doi: 10.1123/jsep.22.4.283 
Nosek, B. (2005). Understanding and using the Implicit Association Test: II. Method variables and construct validity. Personality and Social Psychology Bulletin, 31(2), 166-180. doi: $10.1177 / 0146167204271418$

Oldmeadow, J. A., \& Fiske, S. T. (2010). Social status and the pursuit of positive social identity: Systematic domains of intergroup differentiation and discrimination for high-and low-status groups. Group Processes \& Intergroup Relations, 13(4), 425-444. doi: $10.1177 / 1368430209355650$

Pruett, S. R., \& Chan, F. (2006). The development and psychometric validation of the disability attitude implicit association test. Rehabilitation Psychology, 51 (3), 202-213. doi: $10.1037 / 0090-5550.51 .3 .202$

Rohmer, O., \& Louvet, E. (2009). Describing persons with disability: Salience of disability, gender, and ethnicity. Rehabilitation Psychology, 54(1), 76-82. doi: 10.1037/a0014445

Rohmer, O., \& Louvet, E. (2012). Implicit measures of the stereotype content associated with disability. British Journal of Social Psychology, 51(4), 732-740. doi: 10.1111/j.20448309.2011.02087.x

Rohmer, O., \& Louvet, E. (in press). Implicit stereotyping against people with disability. Group Processes and Intergroup Relations. doi: 10.1177/1368430216638536

Simmons J. P., Nelson L. D., Simonsohn U. (2012). A 21 Word solution. SSRN Electronic Journal, 1-4. doi:10.2139/ssrn. 2160588

Smith, B., \& Sparkes, A. C. (2012). Disability, sport and physical activity: A critical review. In N. Watson, A. Roulstone, \& C. Thomas (Eds.), Routledge handbook of disability studies (pp. 336-347). London: Routledge.

Tyrrell, A., Hetz, S., Barg, C., \& Latimer, A. (2010). Exercise as stigma management for individuals with onset-controllable and onset-uncontrollable spinal cord injury. Rehabilitation Psychology, 55(4), 383-390. doi: 10.1037/a0021539 
Wilson, M. C., \& Scior, K. (2015). Implicit attitudes towards people with intellectual disabilities: Their relationship with explicit attitudes, social distance, emotions and contact. PLoS ONE, 10(9), e0137902. doi: 10.1371/journal.pone.0137902

Wittenbrink, B., \& Schwarz, N. (2007). Implicit measures of attitudes. New York: The Guilford Press

White, M. J., Jackson, V., \& Gordon, P. (2006). Implicit and explicit attitudes toward athletes with disabilities. Journal of Rehabilitation, 72(3), 33-40. 


\section{Appendix}

Figures illustrating the different categories used for the Implicit Associations Tests.

Figures illustrating the category of without disability persons

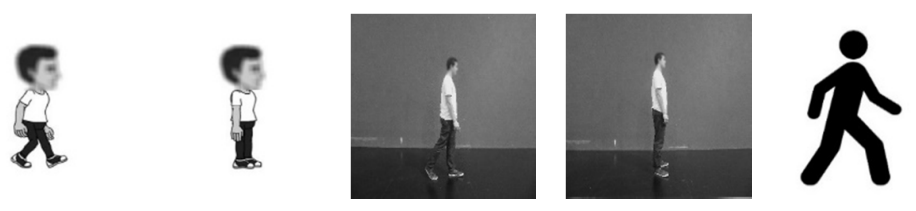

Figures illustrating the category of persons with disability
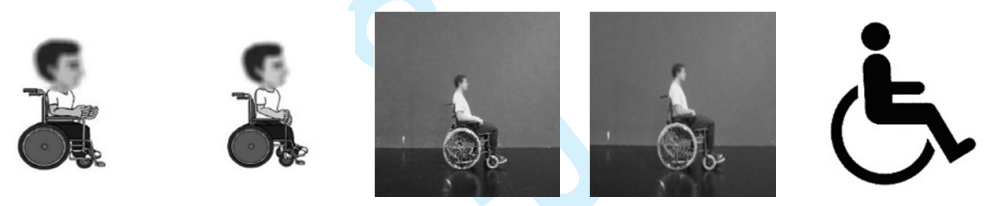

Figures illustrating the category of sports persons with disability
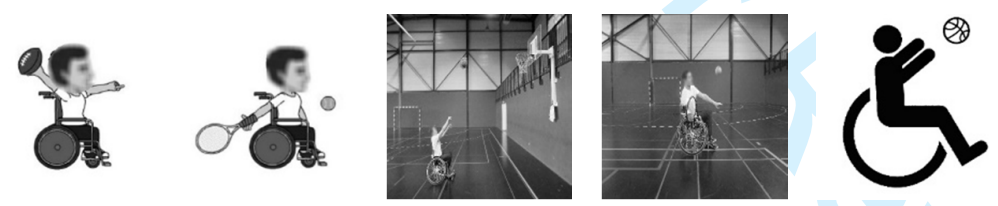